\title{
Bladder Angiosarcoma
}

National Cancer Institute

\section{Source}

National Cancer Institute. Bladder Angiosarcoma. NCI Thesaurus. Code C159671.

A very rare angiosarcoma that arises from the bladder. 